INNOVACIÓN

\title{
Linguagem cinematográfica na formação docente: O ético e a estética na educação
}

\author{
Lenguaje cinematográfico en la formación docente: Ética y estética en la educación
}

Cinematographic language in teacher training: Ethics and a esthetics in education

\author{
Ana Iara Silva de Deus \\ Universidade Federal de Santa Maria, Brasil \\ Patrício Ceretta \\ Universidade Federal de Santa Maria, Brasil \\ Gabriella Eldereti Machado \\ Universidade Federal de Santa Maria, Brasil \\ Valeska Fortes de Oliveira \\ Universidade Federal de Santa Maria, Brasil
}

RESUMO Este texto discorre sobre o cinema na formação de professores permeado pela educação ético-estética. Para tanto, apresenta um breve histórico sobre a educação estética moderna e a linguagem cinematográfica como possibilidade de aproximação da ética e da estética na formação continuada de professores. Desse modo, conceitua-se a ética e a estética inter-relacionando seus conceitos com a formação de professores para pensar possíveis mudanças no campo educacional, utilizando-se do cinema como dispositivo nessa formação. Esse processo ocorre quando a arte se interliga à emoção e ao pensamento, possibilitando a capacidade de colocar-se no lugar do outro para que o educador vivencie diversos papéis. Por isso, esse tema é de grande relevância na formação de professores, principalmente nos dias atuais, quando é encontrado um cenário educacional sucateado e carente de novas investidas para que o educador possa rever-se e repensar sua ação e inserção no âmbito educacional, por meio de experiências sensíveis.

PALAVRAS-CHAVE Educação estética, cinema e formação de professores. 
RESUMEN Este texto reflexiona acerca de la importancia del cine en la formación educativa ético-estética de los profesores. Para ello, presenta un breve resumen histórico acerca de la educación estética moderna y el lenguaje cinematográfico como posibilidad de aproximación de la ética y de la estética en la formación continuada de profesores. De ese modo, conceptualiza la ética y la estética interrelacionando sus conceptos con la formación de professores, proponiendo posibles cambios en el campo educativo, utilizando el cine como dispositivo. Este proceso ocurre cuando el arte se interconecta con la emoción y al pensamiento, posibilitando la capacidad de colocarse en el lugar del otro para que el educador vivencie diversos papeles. Por eso, este tema es de gran relevancia en la formación de profesores, principalmente en los días actuales, en los que encontramos un escenario educativo empobrecido, carente de nuevas perspectivas estimulantes para que el educador pueda rever y repensar su acción e inserción en el ámbito educativo, por medio de experiencias sensibles.

PALABRAS CLAVE Educación estética, cine, formación de professores.

\begin{abstract}
This text discusses the cinema in the formation of teachers permeated by ethical-aesthetic education. In order to do so, it presents a brief history on modern aesthetic education and the cinematographic language as a possibility for the approximation of ethics and aesthetics in the continuous formation of teachers. In this way, he conceptualizes ethics and aesthetics by interrelating their concepts with the formation of teachers to think possible changes in the educational field, using the cinema as a device in this formation. This process occurs when art intertwines with emotion and thought, enabling the ability to put oneself in the other's place so that the educator experiences different roles. Therefore, this theme is of great relevance in teacher training, especially in the present day, when an educational scenario is found that is scrapped and devoid of new ones so that the educator can review and rethink his action and insertion in the educational scope, for experiences.
\end{abstract}

KEYWORDS Aesthetic education, cinema and teacher training.

\title{
A estética do cinema no contexto da formação de professores
}

Pensar a estética do cinema na educação requer impregnar-se, como apontou Schiller (1989), "da contingência dada pela natureza das coisas, para nos intoxicarmos dos rastros da beleza que existem em todas essas coisas". Isso é exatamente o que sugere Fresquet (2013: 26) quando afirma:

A relação com o mundo atravessado pela câmera produz uma determinada vivência para o aprendente/espectador, criador que é fortemente transformadora. O tipo de vivência do cinema na educação revela uma potência da imagem cinematográfica, que supera a visão tradicional linguística, semiótica e semiológica, propiciando no espaço educativo, uma experiência sensível e direta com a obra de arte. 
Essa relação com o mundo permeado pela câmera possibilita novas maneiras de constituição como professor e, igualmente, de estar em aula (Meyer e Vellani, 2014; Hempel, 2015; De Almeida, 2018; Herrero, 2016: De Freitas, 2016; Guimarães, 2013; De Lima Neto e Da Nóbrega, 2018; Granado Palma, 2008; Hilgert e Fischer, 2016; Neto e Ferreira, 2016; Nikolaevna e Nikitin, 2017).

Pensando assim, essa postura instaura um novo olhar sobre o próprio espaço vivido, quase como se fossem colocadas lentes sobre o ambiente em que se está inserido. Para Bergala (2007), essa conexão ocorre quando acontece a eleição, a disposição e o ataque, ou seja, as três operações mentais acionadas quando alguém tem em suas mãos uma câmera para realizar sua criação. Essas etapas são definidas por Bergala (2007: 134) como:

$\mathrm{O}$ ato de criação cinematográfica passa por três operações mentais simples, a eleição, a disposição e o ataque. Essas três ações são específicas no ato de realizar uma filmagem independente de diferenciações técnicas. Essas ações não correspondem a momentos específicos e cronológicos, mas se combinam a cada momento da cena. No cinema, nas diferentes fases do trabalho, tem que eleger, escolher alguma coisa do real, dentre as possibilidades. Na filmagem os atores, a decoração, as cores, os gestos, os ritmos. E na montagem os temas, os sons e os ambientes. A disposição situa as coisas umas em relação com as outras, na filmagem, os atores, elementos da decoração, os objetos, os figurantes etc. $\mathrm{O}$ atacar significa escolher $\mathrm{o}$ ângulo e o ponto de ataque das coisas escolhidas.

Embora Bergala coloque essas três operações mentais de maneira sequencial, elas não podem ser visualizadas cronologicamente, pois essas ações se combinam a cada momento, dialeticamente, durante as etapas do processo criativo. Então, não há uma ordem clara para o início do trabalho com a linguagem cinematográfica.

Para esse autor, a qualidade dessa experiência reside numa única questão, a de colocar em dúvida se realmente essa criação em sala de aula está se confrontando efetivamente com o cinema. Outro fator importantíssimo que faz pensar a estética do cinema na formação é o papel de alteridade que a linguagem cinematográfica propicia aos professores e alunos nas instituições escolares, pois a arte interliga-se com o cinema na escola quando a emoção e o pensamento se unem. Nas palavras de Teixeira (2011: 14):

O cinema pensado como alteridade interroga o já visto, remove o instituído, desloca os olhares, inventa ideias, possibilidades, outros enredos, novas imagens, luminosidades tantas [...]. O cinema deve estar na escola não como um conteúdo curricular e campo de especialidade de um professor, mas de outra maneira, em outra perspectiva, fugindo à racionalidade instrumental e conteúdos a serem aferidos e mensurados pelos profissionais especializados nisso e naquilo. Trata-se, ao revés de um encontro com o cinema como expressividade, como um largo horizonte de possibilidades que permitem a experiência estética. 
No entanto, para que o cinema seja visto e, de fato, abordado dessa forma, é necessário, como recomenda Bergala (2007), propiciar um clima de autonomia, por parte de quem aprende, modificando a "explicação" pela "exposição" de muitos e bons filmes, procurando estabelecer uma cultura cinematográfica. E, para que esse processo ocorra, é imprescindível a mediação educativa que auxiliará a articulação, comparando trechos de filmes, e aguçando a observação das sutilezas, contribuindo para que as experiências estéticas com o cinema aconteçam.

A estética do cinema na formação de professores ocorre quando a arte interliga-se com a emoção e o pensamento, possibilitando a capacidade de colocar-se no lugar do outro para vivenciar inúmeros papéis. Sobre essa questão, Nussbaum assegura que essa é a "capacidade de pensar como seria estar no lugar de outra pessoa, de interpretar com inteligência o relato dessa pessoa e de entender os sentimentos, os desejos e as expectativas que poderia ter essa pessoa" (Nussbaum, 2010: 182; a tradução é nossa). Essa experiência estética de alteridade é possível por meio do cinema na formação. Assim, a arte cinematográfica poderá contribuir com os processos de formação dos professores, por meio das possíveis mudanças que esse processo institui.

Conforme assegura Castoriadis (1982: 400), a "realidade natural" não é apenas aquilo que resiste e não se deixa manejar: ela é também aquilo que se presta à transformação, o que se deixa alterar "condicionalmente" mediante, ao mesmo tempo, seus interstícios livres e sua regularidade. Portanto, o contato com a arte desafia pela sua simples presença, pois a linguagem cinematográfica não reapresenta um conteúdo já sabido. Ao contrário, provoca novas perguntas, cujas respostas só são encontradas ao longo da caminhada.

Assim, interligar a estética do cinema na formação de professores pode potencializar possíveis reflexões sobre as práticas pedagógicas existentes no âmbito escolar e, quem sabe, abrir espaço para que novas ações educativas possam emergir e instituir-se.

Nessa perspectiva, essa aproximação do cinema com o ético-estético na formação de professores potencializa a expressão dos sentimentos no campo educacional suscitando experiências sensíveis aos envolvidos nesse processo (Reia-Baptista, Burn, Reid e Cannon, 2014; Urpí e Vicente, 2008; Ortega Carrillo e Pérez García, 2013; Sáenz, 2015; Penteado, Costa e Rodrigues, 2018; Rifà-Valls, 2011; Rodriguez Terceño, 2014; Pires e Pereira da Silva, 2014). Para Rancière (2009), o sensível é um sistema de evidências que revela a existência de um comum e dos recortes que definem lugares e partes respectivas. Assim, o cinema na formação dos professores pode ser esse comum que Rancière descreve como partilha do sensível no campo educacional.

Migliorin define o cinema na educação como:

O cinema vai para a escola não como texto ou como tema, mas como ato de criação. Não se trata de colocar o cinema na sala de aula porque ele pode dizer me- 
lhor o que já sabemos, mas porque ele tem uma forma sensível singular. Para isso, podemos começar pela materialidade da imagem. O que vemos, as cores, os cortes, o corpo, o olhar o gesto. Assim, é função do professor fomentar uma leitura criativa, não somente analítica e crítica (2015: 28).

Desse modo, a experiência estética com a linguagem cinematográfica, na formação dos professores aproxima-os ao sensível, ao som as imagens e à materialidade do cinema constituindo esquemas de percepções, gostos, julgamentos e imaginações, bem como fomenta uma leitura criativa, crítica e sensível do mundo (Wheeler, 2018; Genovard Roselló, Casulleras Femenia, Gotzens Busquets, 2010; Çengelci, 2013; Areiza Pérez e Betancur Valencia, 2011; Fischer, 2009; Clarembeaux, 2010; Bennett e Kruse, 2015; González Blasco, Moreto e Pessini, 2018; Costa, Branquinho e Pereira 2018).

\section{A Educação ético-estética e suas potencialidades na formação docente: contextualização histórica}

Diante do desafio que a atual realidade educacional impõe, em relação ao processo formativo docente e ao próprio ensino-aprendizagem, faz-se necessário mais uma vez pautar a importância da ética e da estética no professor formativo, a partir de uma linguagem que envolva muito mais que a simples racionalidade, mas permita acessar outras inteligências e novas maneiras de perceber o mundo.

Nesse sentido, assim argumenta Hermann sobre a ética e a estética na formação de professores: "a estética e a experiência estética são aqui tematizadas com o objetivo de demonstrar suas possibilidades de comunicação com a ética e de operar como categoria conceitual decisiva para uma educação ético-estética" (2010: 31).

Desse modo, pensar a ética e a estética na formação de professores, permeadas pela sétima arte, como potencialidades no cenário educacional. Essa aproximação coloca o educador no centro do processo autoformativo, pois a experiência estética do cinema na educação age como dispositivo de formação, exatamente porque a linguagem cinematográfica mobiliza, desestabiliza e põe em cheque os saberes instituídos, rompendo com a visão do sistema escolar, como espaço altamente regrado, com currículos fechados, sem possibilidade de uma discussão transversal e interdisciplinar. Assim, é importante esclarecer o conceito de Estética definindo a epistemologia da palavra, pelo Dicionário de Filosofia:

Esse termo designa a ciência (filosofia) da arte e do belo. O nome foi introduzido por Baumgarten por volta de 1750, no livro A esthética, em que defendia a tese pela qual objeto da arte são as representações confusas mas claras, isto é, sensíveis mas "perfeitas", enquanto objeto do conhecimento racional são as representações distintas (os conceitos). O nome significa propriamente "Doutrina do conhecimento sensível”; e Kant, que também fala [...] de um juízo estético que é justamente o 
juízo sobre a arte e sobre o belo. Dessa maneira, podemos entender três dimensões da arte, quais sejam "imitação" (mimesis'), "criação" e "construção" (Abbagnamo, 1962: 348).

Assim, o próprio termo apresenta duas vertentes de pensamento: uma que remonta ao conceito da arte e do belo como fator sensível e outra que apresenta o belo e o bom. Desse modo, pode-se perceber que esses dois conceitos norteiam o significado da palavra desde sua origem.

Assim, inicia-se a tessitura desta escrita com a educação estética moderna, que surgiu a partir do século XVIII, ressaltando, entretanto, que a arte já existia desde a época mais remota em todos lugares, e a estética apresenta essa conceituação somente a partir desse século. Jimenez afirma que:

A palavra arte, herdeira desde o século XI, de sua origem latina, ars - atividade, habilidade - designa até o século XV, no Ocidente, apenas um conjunto de atividades ligadas à técnica, ao ofício, à perícia, isto é, tarefas essencialmente manuais. A própria ideia de estética, no sentido moderno, aparece somente no momento em que a arte é reconhecida e reconhece, através de seu conceito, como atividade intelectual, irredutível a qualquer outra tarefa puramente técnica. Assim, a estética, que inaugura sua fase moderna a partir de 1750, não se declarou autônoma de um dia para outro unicamente pela graça do filosofo alemão Baumgarten. Sua fundação, enquanto ciência, é o resultado de um longo processo de emancipação que, pelo menos no Ocidente, concerne ao conjunto da atividade espiritual, intelectual, filosófica e artística, sobretudo a partir da Renascença (1999: 32).

Como se pode perceber, antes do século XVIII, a arte estava ligada apenas às questões puramente técnicas dos artesões. Nesse sentido, Jimenez (1999) refere o pensamento de que a criação artística não é somente divina, mas necessita de uma ação humana, e esse conceito se impôs depois de muitos debates teológicos e filosóficos, pois na sua origem não se referia direta nem imediatamente ao domínio da arte. Somente no século XVII, o belo se libertou dos valores do bem e do verdadeiro e, no final do século XVIII, a imitação fiel da natureza não foi mais considerada a única finalidade do artista.

O movimento das ideias que se afirmaram no século XVIII e que conduziu à libertação que se acabou de ver não se impôs por si mesmo, mas sofreu modificações desde a Idade Média, em razão das condições sociais, econômicas e políticas da época. A partir dessas transformações, novas concepções se concretizaram na realidade, como enfatiza Baumgarten: A Estética (como teoria das artes liberais, como gnoseologia inferior, como arte de pensar de modo belo, como arte do análagon da razão) é a ciência do conhecimento sensitivo. [...] destacam-se algumas aplicações especiais,

1. Termo utilizado por Platão e Aristóteles como imitação do real. Ver Ricoeur (1995: 139). 
a saber: 1) a Filosofia; 2) a Hermenêutica; 3) Exegética; 4) a Retórica; 5) a Homilética; 6) a poética; 7) a musical, etc. (Baumgarten, 1993: 95-96).

Desse modo, a educação estética moderna configurou-se, no final da Idade Moderna com Baumgarten, que iniciou os primeiros estudos sobre o tema. No entanto, foi Nelson Goodman apud Jimenez (1999), que questionou sobre a razão de, desde Baumgarten, a estética não ter sido posta rigorosamente no mesmo plano do conhecimento lógico. Com esse questionamento, iniciou seus estudos com o fim de reabilitar a estética aos olhos dos cientistas, mostrando que não há diferença fundamental entre a experiência científica e a experiência estética.

Para Jimenez apud Goodman (1999), as experiências estéticas não estão mais baseadas nas ideias, nos fantasmas ou nas paixões expressas por obras de arte, mas repousam na capacidade de ver que a obra de arte é um sistema simbólico e de compreender como funciona esse sistema de símbolos. Como esclarece Jimenez:

A estética analítica não define mais a arte em função do que ela é em sua essência suposta ou futura, mas segundo o que ela anuncia em sua existência e no que dizemos dela. O que é expresso por uma obra de arte, seu conteúdo, sua ideia, portanto, não é levado em consideração. Goodman afasta assim todas as noções "clássicas" da filosofia da arte tradicional, como o prazer, o gozo e outros afetos. As questões relativas ao gosto, à beleza, ao julgamento e ao valor das obras tornam-se secundárias, chamados por Goodman "sintoma da estética", que permitem distinguir precisamente o estético e o não estético (1999: 368).

A educação estética evoluiu pelos estudos de alguns pensadores, como, por exemplo, a educação estética do homem de Friedrich Von Schiller, o qual publicou $27^{2}$ cartas sobre o tema, no período de setembro de 1794 a junho de 1795. Artista, poeta, escritor dramático, Schiller defendeu a ideia de que sua arte e a arte em geral não são inúteis. Dizia ele:

Permitirei que vos exponha numa série de cartas os resultados de minhas investigações sobre o belo e a arte. Sinto vivamente o peso de tal empreendimento, mas também seu encanto e sua dignidade. Falarei de um objeto que está em contato imediato com a melhor de nossa felicidade e não muito distante da nobreza moral da natureza humana. Defenderei a causa da beleza perante um coração que sente seu poder e o exerce, e que tomará a si a parte mais pesada de meu encargo nesta investigação que exige, com igual frequência, o apelo não só a princípios, mas também a sentimentos (Schiller, 1989: 19).

Com suas 27 cartas, esse autor elaborou um tratado estético e formulou uma pro-

2. Esse material está disponível no livro de Schiller, A educação estética do Homem numa série de cartas. 
posta reflexiva que vê o homem como organismo vivo e em constante transformação no seu compromisso com a prática política, como afirma na carta IX:

Arte e Ciência são livres de tudo o que é positivo e que foi introduzido pelas convenções do homem; ambas gozam de uma absoluta imunidade em face do arbítrio humano. O legislador político pode interditar seu território, mas nunca nele imperar. Pode proscrever o amigo da verdade, mas esta subsiste; pode diminuir o artista, mas não falsificar a arte [...] A humanidade perdeu sua dignidade, mas a arte a salvou e conservou em pedras insignes; a verdade subsiste na ilusão, da cópia será refeita a imagem original. Do mesmo modo que sobreviveu à natureza nobre, a arte nobre também marcha à frente deste no entusiasmo, cultivando e estimulando [...] mas como o artista se resguarda das corrupções de sua época, que o envolvem por todos os lados? Desprezando o seu juízo. Deve elevar os olhos para sua dignidade e lei, não os baixar para a felicidade e a necessidade (Schiller, 1989:50).

Nesse fragmento de Schiller, percebe-se um caráter fortemente político ao dizer que a arte e a ciência gozam de imunidade e estão livres das imposições dos homens, pois o legislador político pode interditar seu território, mas não imperar nele. Assim, segundo Silva (2001), no entendimento de Schiller, o homem deve ser lido como uma obra de arte, porque é nesta que está manifesta a totalidade de todo o saber livre, fazendo vibrar no contingente logicamente produzido a universalidade da transcendência.

A qualidade estética no homem é aquele bem novo que lhe permite a autodeterminação, porque lhe restitui a liberdade de fazer de si instrumento em evolução constante. Ser estético é superar a contingência dada pela natureza das coisas e intoxicarse dos rastros da beleza que existem em tudo.

Dessa maneira, Schiller contribuiu significativamente para o surgimento da educação estética, ou, como afirma Gennari,

La pedagogía estética ${ }^{3}$ nace, por tanto, con Schiller. Gracias a su obra y a su pensamiento se crea un nuevo paradigma según el cual la educación estética puede formar al hombre completamente y sacar a la superficie la humanidad que habita en él (1997: 124).

A pedagogia estética surgiu, então, com esse pensador, que acredita na formação completa do homem pelo desenrolar das disposições estéticas da alma humana, as quais ocorrem, segundo Gennari (1997), pela interação da lei moral com a razão, que se harmoniza com a sensibilidade por meio da beleza. Assim, esse elemento estético conduz o homem à liberdade da razão, da moral e, finalmente, da política. Gennari

3. "A pedagogia estética nasce, portanto, com Schiller. Graças a sua obra e seu pensamento se cria um novo paradigma segundo o qual a educação estética pode formar o homem completamente e trazer à superfície a humanidade que habita nele" (Gennari, 1997: 124; tradução das pesquisadoras). 
afirma que: A dimensão estética ${ }^{4}$ compromete a vida dos indivíduos e da comunidade, influi em toda forma de vida e todo momento da história (1997: 124) [tradução das pesquisadoras]. Essa influência e comprometimento passam necessariamente pela experiência estética que as pessoas fazem, uma vez que toda experiência traz em sua base a cosmovisão do indivíduo.

O conceito da "cosmovisão", que nos é familiar e que surge pela primeira vez em Hegel, na Fenomenologia do Espírito, para caracterizar a complementação postulatória da experiência ética fundamental em uma ordem moral do mundo [...], só irá encontrar sua genuína cunhagem na estética. É a multiplicidade e a possível mudança das cosmovisões que acabaram emprestando ao conceito "cosmovisão" esse tom com que estamos familiarizados (Gadamer, 1999: 170).

As experiências feitas impedem um posicionamento diante daquilo que desafia, $\mathrm{e}$ conduz a uma reflexão ética ampliada, e implica uma questão hermenêutica e inevitável de verdade. Para Gadamer:

a experiência estética representa um testemunho. O que nos importa, portanto, é ver a experiência da arte de tal maneira que venha a ser entendida como experiência. A experiência da arte não deve ser falsificada como um fragmento da formação estética que está na sua posse e, com isso, não deve ter neutralizada sua reivindicação própria. [...] nisso reside uma consequência hermenêutica de longo alcance, na medida em que todo encontro com a linguagem da arte é um encontro com um acontecimento não acabado e, ela mesma, uma parte desse acontecimento. É a isso que se tem de pôr em relevo contra a consciência estética e contra a sua neutralização da questão da verdade (1999: 171; o itálico é do original).

Esse acontecimento de longo alcance a que Gadamer se refere pode ser expresso na relação que a ética e a estética estabelecem. Dado que o tema da ética apresenta certa ambiguidade, sempre é bom lembrar que moral se refere a "costume" ou "costumes", no sentido de conjunto de normas ou regras adquiridas por hábito [...] já ética tem a ver com "modo de ser" ou "caráter" (Vázquez, 2005: 24). Por outro lado, pode-se dizer que ética é uma disciplina filosófica, a Filosofia moral ou Ética, que, por sua vez, contém uma variedade de teorias éticas diferentes, e até contrapostas entre si (Cortina, 2009: 15). Mesmo que esses autores consagrados façam uma distinção sistemática, outros não têm essa preocupação, mesmo que haja consequências práticas no fato de adotar uma distinção ou não, seja para uma leitura sob a ótica da estética ou apenas interpretativa como tarefa da ética.

4. "La dimensión estética compromete la vida de los individuos y la de la comunidad, influye en toda forma de vida y en todo momento de la historia. El universalismo estético de Schiller ya está trazado: su base reside en la belleza, garante auténtica de la moralidad, puesto que es expresión de una armonía (no original) entre ley y naturaleza”. 
Do ponto de vista filosófico, a ética interpreta, discute e problematiza valores morais e a fundamentação do agir moral. Ela nasce da reflexão dos costumes e se origina no espírito grego até chegar à tematização daquilo que chamamos bem viver ou bem agir. Do entendimento do que é bem viver decorrem normas com vigência incondicional e que integram o homem na totalidade social. De modo amplo, na tradição filosófica ocidental, a ética é a busca de uma compreensão racional dos princípios que orientam o agir humano (Hermann, 2005: 15).

O agir humano, de modo particular, se expressa por meio do teatro, do cinema, e de toda expressão artística. Estas têm a tarefa de provocar a reflexão e a mudança de comportamento diante do tema proposto, e instigam a pensar outras possibilidades antes impensadas conforme a cosmovisão dos estudantes ou do professor em questão. Nessa mesma visão, a ética desempenha uma relação moral que a pessoa ou o grupo social vive, ou seja, amplia o horizonte de compreensão, mudando o próprio comportamento. Talvez esta seja justamente a aproximação da ética e da estética no processo de formação: provocar uma mudança interior, para, em seguida, mudar a prática pedagógica, potencializando novas vivências e experiências formativas.

Para Maffesoli (1995), esse processo de compreensão da realidade e do meio circundante assume as mais diversas formas: esporte, música, religião, turismo, lazer, consumo e não remete a uma cultura, como se afirmou com força neste fim de século.

Trata, portanto, da capacidade de usufruir de uma experiência estética. Conforme argumenta Villela:

Para que se possa viver uma experiência estética, antes de tudo, é preciso assumir uma atitude estética, ou seja, assumir uma posição, uma postura que constitua e configure a nossa percepção. Não como uma intencionalidade, uma premeditação, uma antecipação racional do que está por vir, mas como uma disposição contingente, uma abertura circunstancial ao mundo. A premeditação é da ordem da atitude prática, utilitária, funcional, é quando nos dirigimos para o mundo com vista a determinados fins, considerando as coisas e os acontecimentos como meios úteis para atingir um fim. A atitude estética é uma atitude desinteressada, é uma abertura (2012: 20; o itálico é do original).

No entanto, para ocorrer essa atitude estética, é necessário estar aberto para o mundo circundante, e não apenas percebê-lo, mas, sobretudo, os efeitos que produzem as percepções nos sentimentos. Ou, nas palavras de Duarte Júnior (2001), "O sentido do sentido".

Dessa forma, é preciso extrair os significados mais profundos no que diz respeito aos sentimentos e ao senso de realidade interior e exterior, para que as potencialidades possam aflorar no dia a dia da formação. Por isso, discute-se a experiência estética na formação de professores, por meio do cinema como possibilidade de uma ação ético-estética na vida dos professores. 


\section{0 ético e a estética na formação de professores: entrelaçamentos possíveis}

Pensar sobre a dimensão ético-estética na formação de professores nos dias atuais é relevante, pois essa temática convida a rever e repensar o campo de ação e atuação docente, e remete à estética da existência humana.

Para Gadamer, esse processo ocorre:

Na medida em que o estágio estético da existência se mostra em si insustentável, reconhece-se que o fenômeno da arte coloca uma tarefa à existência: a de, em face da atualidade exigente e arrecadadora da respectiva impressão estética, alcançar a continuidade da auto-evidência, que somente a existência humana (Dasein) pode sustentar [...] Inclusive aquilo que está fechado à nossa compreensão é experimentado por nós mesmos como algo que limita e pertence, assim, à continuidade da auto-evidência, na qual a existência humana se movimenta (Gadamer, 1999: 167).

Dessa maneira, a estética pode ser entendida como uma tendência da existência que potencializa o caráter ficcional da realidade, trazendo o contexto do estranhamento, inovação e pluralidade (Hermann, 2005). Nesse sentido, a relação entre ética e estética se constitui por meio de novas exigências em relação à pluralidade e permite transcender fronteiras da interpretação.

Como menciona Hermann,

A estruturação estética da educação pode ampliar de forma significativa a consciência ética, liberando novas formas de sensibilidade que temos deixado de lado. $\mathrm{O}$ horizonte do questionamento ético se desloca para o estético como um modo de enfrentar o caráter restritivo das justificações racionais e expor a fragilidade e os limites de uma ética que pretenda excluir a expressividade estética (2005: 24).

A educação, por meio do sentido ético e estético, entrelaça-se com a desconstrução das representações instituídas construindo movimentos instituintes. E, nessa óptica, o sujeito instaura novas significações sociais imaginárias abrindo espaços para que o instituinte se manifeste. Castoriadis diz que: "O imaginário social como instituinte constrói significações imaginárias sociais. Logo, cada sociedade institui-se a seu modo" (2007: 36). Dessa maneira, por meio das significações imaginárias sociais podem-se instaurar novas formas de ser e estar na sociedade.

Assim, a formação estética ocorre por processos que englobam sensações, sensibilidades, percepções, e o desenvolvimento de outros sentidos para o conhecimento. E a experiência estética e o imaginário complementam-se na medida em que utilizam de outros critérios para determinar o seu fazer e ser científicos, pois o imaginário se relaciona com a sociedade por meio de significações que produzem significados às práticas sociais materializadas de diversas formas (Oliveira, 2014).

Por isso, a sociedade encontra no estético e na ética uma possibilidade de con- 
versar com outros modos de relação dos sujeitos com o mundo e a vida exatamente como ela é, permitindo que as experiências estéticas possam ser vivenciadas no âmbito do pensamento e da ação.

\section{Considerações finais}

Diante do exposto, pode-se concluir que o papel da ética e da estética no campo da formação de professores é relevante, pois as experiências estéticas ocorrem quando se entra em contato com o que afeta o indivíduo, com o que ele se deixa afetar. Da mesma forma que a discussão ética se deixa afetar e é permeada pela ação moral das pessoas envolvidas, esse processo ético-estético ultrapassa o conceito do belo das obras de arte, como se viu ao longo deste texto, e vai além, ou melhor, acontece nas percepções do dia a dia, nas sutilezas e da forma como as pessoas se relacionam com os fatos que chegam a elas.

Desse modo, pela experiência ético-estética, é possível entrar em contato com a sensibilidade pessoal e trazer à tona para o campo educacional as dimensões sensíveis e coletivas que decorrem do cinema como dispositivo de formação para que essas percepções e sentimentos ocorram quando as pessoas se colocam frente à tela e refletem sobre o que veem, ouvem e sentem o que, às vezes permite alterar os posicionamentos.

Nessa perspectiva, a educação ético-estética interliga-se com a linguagem cinematográfica na formação de professores e possibilita novas maneiras de o professor estar em aula, e múltiplos olhares. Desconfigura-se, assim, a ideia de alguém que ensina e o outro aprende, pois a dinâmica do trabalho com o cinema na educação viabiliza uma atmosfera de compartilhamento, assim como permite a discussão sobre a ética, em que não há uma hierarquia, mas todos mergulham em um mundo de imagens, sons, compreensões, opiniões e movimentos.

Com estas reflexões, não se pretende propor um "salvacionismo" para o campo educacional. É possível, entretanto, que essas aproximações potencializem novas configurações na prática docente pelo viés da criação e reinvenção que o cinema mobiliza aos envolvidos.

Portanto, a partir desta ótica, a contribuição do cinema para a formação éticoestética dos professores ocorre quando provoca nos docentes a capacidade de colocar-se no lugar do outro, ou seja, a alteridade que as narrativas fílmicas propiciam mobilizando-os a adentrarem em sua docência, revendo-se nos personagens, e convocando-os a refletirem sobre suas práticas educativas. Por isso, a relevância desse tema na formação de professores, principalmente nos dias atuais, quando se encontra um cenário educacional sucateado e carente de novas investidas para que o educador possa rever-se e repensar sua ação e inserção no âmbito educacional, por meio das experiências sensíveis com a linguagem cinematográfica na formação docente. 


\section{Referências}

Abbagnano, Nicola (1962). Dicionário de filosofia. $2^{\text {a }}$ ed. São Paulo: Marte Jau.

Areiza Pérez, Érica Elexandra y Diela Bibiana Betancur Valencia (2011). "Maestros narrados en el cine: Una mirada entreabierta sobre la escuela, el saber y la formación”. MAGIS. Revista Internacional de Investigación en Educación, 4 (7): 187-198.

Baumgarten, Alexander Gottlieb (1993). Estética: a lógica da arte e do poema, Petrópolis, RJ: Vozes.

BennetT, Gregory e Jan Kruse (2015). "Teaching visual storytelling for virtual production pipelines incorporating motion capture and visual effects" SIGGRAPH Asia 2015 Symposium on Education. ACM.

Bergala, Alain (2007). La hipothèse del cine: Pequeño tratado sobre la transmissión del cine em la escuela y fuera de ella. Barcelona: Cahiers du Cinéma.

Castoriadis, Cornelius (1982). A instituição imaginária da sociedade. Rio de Janeiro: Paz e Terra.

-. (2007). Sujeito e verdade no mundo social histórico. Rio de Janeiro: Civilização Brasileira.

Çengelci, Tuba (2013). "Social Studies Teachers' Views on Learning Outside the Classroom". Educational Sciences: Theory and Practice, 13 (3): 1.836-1.841.

Clarembeaux, Michel (2010). "Educación en cine: memoria y patriotismo". Comunicar. Revista Científica Iberoamericana de Comunicación y Educación, 35: 25-32.

Cortina, Adela (2009). Ética. $2^{a}$ ed. São Paulo: Loyola.

Costa, Rafael Nogueira, Fátima Teresa Branquinho y Celso Sanchez Pereira (2018). "Produção audiovisual na formação de professores-pesquisadores: olhares compartilhados sobre o Parque Nacional da Restinga de Jurubatiba”. Desenvolvimento e Meio Ambiente, 45: 258-273.

De Almeida, Rogério (2018). "Cinema, educação e imaginários contemporâneos: estudos hermenêuticos sobre distopia, niilismo e afirmação nos filmes $\mathrm{O}$ som ao redor, O cavalo de Turim e Sono de inverno". Educação e Pesquisa, 44:11-18.

De Freitas, Elizabeth (2016). "The moving image in education research: Reassembling the body in classroom video data". International Journal of Qualitative Studies in Education, 29 (4): 553-572.

De Lima Neto, Avelino Aldo e Terezinha Petrucia Da Nóbrega (2018). "Reaprender a ver o mundo: o cinema como educação do olhar". Educação e Pesquisa, 44:1-22.

Duarte Júnior, João Francisco (2001). Fundamentos estéticos da educação. Campinas, São Paulo: Papirus.

Fischer, Rosa María (2009). "Docência, cinema e televisão: questões sobre formação ética e estética”. Revista Brasileira de Educação. Belo Horizonte, 14 (40): 93-102.

Fresquet, Adriana (2013). Cinema e educação: Reflexões e experiências com profes- 
sores e estudantes de educação básica, dentro e "fora" da escola. Belo Horizonte: Autêntica.

GadAmer, Hans-Georg (1999). Verdade e método: Traços fundamentais de uma hermenêutica filosófica. $3^{\text {a }}$ ed. Petrópolis, RJ: Vozes.

Gennari, Mário (1997). La educación estética: Arte e literatura. Barcelona: Paidós.

Genovard Rosselló, Cándido, David Casulleras Femenia e Concepción Gotzens Busquets (2010). "La calidad docente en el cine: contrastes entre la ficción y el documental". Revista Española de Pedagogía, 68 (245): 5-21.

González Blasco, Pablo, Graziela Moreto e Leo Pessini (2018). "Using Movie Clips to Promote Reflective Practice: a Creative Approach for Teaching Ethics". Asian Bioethics Review, 10 (1): 75-85.

Granado Palma, Manuel (2008). "La otra educación audiovisual”. Comunicar. Revista Científica Iberoamericana de Comunicación y Educación, (31): 563-570.

Guimarães, Denise (2013). "O filme o contador de histórias e as lições da pedagogia do amor”. Educação e Sociedade, 34 (123): 591-610.

Hermann, Nadja (2005). Ética e estética: a relação quase esquecida. Porto Alegre: EDIPUCRS (Coleção filosofia): 193.

-. (2010) Pluralidade e ética em educação. Rio de Janeiro: DP \& A.

Hempel, Monty (2015). "The uses and limitations of film in environmental education". Journal of Environmental Studies and Sciences, 5 (2): 237-239.

Herrero, Carmen (2016). "The Film in Language Teaching Association (FILTA): a multilingual community of practice”. Elt Journal, 70 (2):190-199.

Hilgert, Ananda Vargas e Rosa Maria Bueno Fischer (2016). "Aesthetic Education, cinema and otherness". Cadernos de Pesquisa, 46 (162): 1.234-1.257.

Jimenez, Marc (1999). O que é estética? São Leopoldo: Unisinos.

Maffesoli, Michel (1995). A contemplação do mundo. Porto Alegre: Artes e Ofícios.

Meyer, Karen Ann e Al-Munir Vellani (2014). "Cinema and Pedagogy: An Urban Education Seminar". Journal of Curriculum and Pedagogy, 11 (2): 107-121.

Migliorin, Cezar (2015). Inevitavelmente Cinema: Educação, política e mafuá. Rio de Janeiro: Beco do Azougue.

Neto, Daniela e Luciano Ferreira (2016). "O cineclubismo como ferramenta didática da educação em direitos humanos: estudo de caso em um curso de graduação em relações internacionais no Brasil". Revista Pedagogía Universitaria y Didáctica del Derecho, 3 (2): 5-29.

Nikolaevna Likhanova, Elena e Oleg Denisovich Nikitin (2017). "Psychologicalpedagogical Potential of Media Culture: Principles and Prospects for the Development of Cinema Pedagogy". Rupkatha Journal on Interdisciplinary Studies in Humanities, 9 (3): 36-51.

Nussbaum, Martha (2010). Sin fines de lucro. Por qué la democracia necesita de las humanidades. Tradução de María V. Rodil. Buenos Aires: Katz. 
Oliveira, Valeska Fortes de (2014). "Imaginário, cotidiano e educação: por uma ética do instante" Cadernos de Educação. FaE/PPGE/UFPel. Pelotas 48 (18): 18-31.

Ortega Carrillo, José Antonio e Álvaro Pérez García (2013) "El cine digital en la formación inicial del profesorado: una experiencia innovadora ralizada en la Universidad de Granada”. Educación XXI, 16 (2): 297-320.

Penteado, Regina Zanella, Belarmino Cesar Guimarães da Costa, e Pedro Henrique Giambroni Neves Rodrigues (2018). "Imaginários no cinema de animação: estetização de corpos na interface do cuidado de crianças e adolescentes”. Saúde e Sociedade, 27: 381-397.

Pires, Maria da Conceição e Sergio Luiz Pereira Da Silva (2014). "O Cinema, a Educação e a construção de um Imaginário Social Contemporâneo”. Educação e Sociedade, 35 (127): 607-616.

Ranciére, Jacques (2009). A partilha do Sensível: Estética e política. São Paulo: Exo experimental.

Reia-Baptista, Vitor, Andrew Burn, Mark Reid e Michell Cannon (2014). "Literacía Cinematográfica: Reflexión sobre los modelos de educación cinematográfica en Europa”. Revista Latina de Comunicación Social, 69: 354-367.

Ricoeur, Paul (1995). Tiempo y narración. I: Configuración del tiempo en el relato histórico (Vol. 1). Siglo XXI.

RifÀ-VAlls, Montserrat (2011). “Experimenting with Visual Storytelling in Students' Portfolios: Narratives of Visual Pedagogy for Pre-Service Teacher Education”. International Journal of Art and Design Education, 30 (2): 293-306.

Rodríguez Terceño, José (2014). "El cine en la realidad de las aulas/Cinema in the classroom reality". Historia y Comunicación Social, 19: 565-574.

SÁEnz, María Jimena (2015). "Derecho... ; al cine! Crónicas de experiencias cinematográficas en el aula”. Academia. Revista sobre Enseñanza del Derecho de Buenos Aires, 13 (25): 217-234.

Silva, Jorge Anthonio (2001). O fragmento e a síntese, a estética objetiva de Schiller. São Paulo: Perspectiva.

SCHILler, Friedrich (1989). A educação estética do homem numa série de cartas. São Paulo: Iluminuras.

TeIXeIra, Inês (2011) "Assunção de Castro". Revista Contemporânea de Educação, 5 (10).

URPÍ, Carmen e Jaione Vicente (2008). "La formación en la cultura audiovisual. Un taller de cine como propuesta pedagógica”. Estudios sobre Educación, 14: 85-104.

VÁzquez, Adolfo Sánchez (2005). Ética. $27^{\mathrm{a}}$ ed. Rio de Janeiro, RJ: Civilização Brasileira.

Villela, Marcos Pereira (2012). "Percepção, estética e formação: o sensível e a experiência do atual". Em Arte e filosofia na mediação de experiências formativas con- 
temporâneas, José Albio Moreira de Sales, Dinamara Garcia Feldens. Fortaleza: EDUECE.

WHEeler, Duncan (2018). "Las adaptaciones cinematográficas como (posible) herramienta pedagógica”. Anuario Lope de Vega, 24: 260-287.

\section{Sobre os autores}

Ana Iara Silva de Deus é Possui graduação em Pedagogia, pós-graduada em Educação Infantil, Arteterapeuta, Mestrado em Educação. Atualmente é doutoranda do PPGE da Universidade Federal de Santa Maria. Integra o grupo de Pesquisa em Educação e Imaginário Social-GEPEIS da UFSM. É Pesquisadora Caps da UFSM. O seu endereço de e-mail é anaiaradeus@hotmail.com

Patrício Ceretta é Possui graduação (licenciatura) em Filosofia- PUC de Porto Alegre; Bacharelado em Teologia pela Escola Superior de teologia e Espiritualidade Franciscana - ESTEF. Atualmente Mestrando do do PPGE da Universidade Federal de Santa Maria. O seu endereço de e-mail é patricioceretta@hotmail.com

Gabriella Eldereti Machado é Licenciada em Química pelo Instituto Federal de Educação, Ciência e Tecnologia Farroupilha Campus Alegrete; Especialista em Educação Ambiental pela Universidade Federal de Santa Maria; Mestranda em Educação na Universidade Federal de Santa Maria. O seu endereço de e-mail é gabriellaelderete@hotmail.com

Valeska Fortes de Oliveira é Professora Dr. responsável pelo departamento de Fundamentos da Educação na Universidade Federal de Santa Maria. Coordenadora do Grupo de Estudos e Pesquisa em Educação e Imaginário Social-GEPEIS-UFSM. O seu endereço de e-mail é vfortesdeoliveira@gmail.com 
La Revista Pedagogía Universitaria y Didáctica del Derecho (RPUDD) es una publicación científica semestral que contribuye a la reflexión multidisciplinaria sobre pedagogía universitaria y didáctica del derecho, para la formación y consolidación de esta área de investigación; así como a la difusión de prácticas innovadoras en la enseñanza-aprendizaje del derecho considerando el contexto nacional e internacional. Es una publicación electrónica internacional con una codirección entre Brasil y Chile.

\author{
DIRECTORA \\ María Francisca Elgueta Rozas \\ Universidad de Chile \\ DIRECTOR \\ Renato Duro Dias \\ Universidad Federal de Rio Grande, Brasil \\ SITIO WEB \\ pedagogiaderecho.uchile.cl \\ CORREO ELECTRÓNICO \\ rpedagogia@derecho.uchile.cl \\ LICENCIA DE ESTE ARTÍCULO
}

Creative Commons Atribución Compartir Igual 4.o Internacional

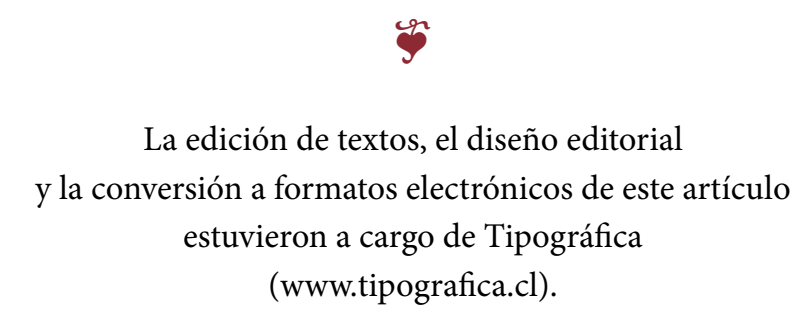

